\title{
Erratum to: Does saturable formation of gemcitabine triphosphate occur in patients?
}

\author{
Lai-San Tham $\cdot$ Ling-Zhi Wang $\cdot$ Ross A. Soo $\cdot$ \\ How-Sung Lee $\cdot$ Soo-Chin Lee $\cdot$ Boon-Cher Goh • \\ Nicholas H. G. Holford
}

Published online: 15 January 2015

(C) Springer-Verlag Berlin Heidelberg 2015

Erratum to: Cancer Chemother Pharmacol

(2008) 63:55-64

DOI 10.1007/s00280-008-0707-9

The author would like to correct the errors in the publication of the original article. The corrected details are given below for your reading.

Equations 1 and 3 should read as:

$$
\begin{aligned}
& \mathrm{LBM}=\mathrm{LBM}_{\mathrm{MAX}} \times \mathrm{HT}^{2} \times\left(\frac{\mathrm{WT}}{\mathrm{WT}_{50} \times \mathrm{HT}^{2}+\mathrm{WT}}\right) \\
& \mathrm{LBM}_{\mathrm{STD}}=\mathrm{LBM}_{\mathrm{MAX}} \times 1.76^{2} \times\left(\frac{70}{\mathrm{WT}_{50} \times 1.76^{2}+70}\right)
\end{aligned}
$$

The online version of the original article can be found under doi:10.1007/s00280-008-0707-9.

L.-S. Tham · L.-Z. Wang · R. A. Soo · S.-C. Lee · B.-C. Goh Department of Hematology-Oncology, National University Hospital, Singapore, Singapore

\section{L.-S. Tham $(\bowtie)$}

Lilly-NUS Centre for Clinical Pharmacology Pte Ltd, Level 6, Centre for Clinical Research (MD11), National University of Singapore, Yong Loo Lin School of Medicine, 10 Medical Drive, Singapore 117597, Singapore e-mail: tham_lai_san@lilly.com

\section{H.-S. Lee}

Department of Pharmacology, Yong Loo Lin School of Medicine,

National University of Singapore, Singapore, Singapore

N. H. G. Holford

Department of Pharmacology and Clinical Pharmacology,

University of Auckland, Auckland, New Zealand 